\title{
ALVEOLAR BONE MORPHOLOGY AND REMODELING PARAMETERS IN THE SITES OF CONGENITALLY MISSING TEETH. A PILOT STUDY
}

\author{
Heba M Hakam* and Dina S. Abd Elfatah**
}

\begin{abstract}
Aim of the study: The cause of a tooth loss may have an impact on the bone quality at this specific site affecting its Osseo integrative potential. The present study was designed to investigate bone quality and activity in implant fixation sites of congenitally missing teeth compared to others of healed extraction ones.
\end{abstract}

Methods: 10 core biopsies were collected during implant fixation procedure; 5 from sites of healed extraction and 5 from sites of congenitally missing un-grafted ridge. They were all from the same jaw with no predilection of anterior or posterior. The specimens were processed for histological, morphometric \& gene expression of RANKL \& vitamin D receptors (VDR).

Results: histological examination with hematoxylin and eosin showed different bone architecture between the two groups with apparent more intact appearance of the healed extraction group. histomorphometry revealed significant difference between the two groups in the total bone area percentage in favor of the healed extraction group. gene expression values of vitamin D receptors, as well as RANKL, recorded a significant decrease in the congenitally missing samples when compared to the healed extraction ones.

Conclusion: the results of the present work suggest the possible effect of cause of tooth loss on the quality of the residual bone which may affect the osteointegration potential in the area that reflects on implant survival rates. More detailed investigation is recommended to include: different areas, different gender as well as involving more growth factors.

KEY WORDS: congenitally missing teeth, vitamin D receptors, RANKL.

* Ass. Professor of Oral Biology, Faculty of Dentistry, Cairo University

** Professor of Medical Biochemistry \& Molecular Biology, Faculty of Medicine, Cairo University. 


\section{INTRODUCTION}

Congenitally missing teeth are often encountered in dental practice when patients seek for help. Single tooth implant is one of the suggested treatments of such conditions for being esthetic and more conservative for adjacent teeth ${ }^{1}$. Congenital teeth missing was reported to be associated with malocclusion, defective bone growth and periodontal problems ${ }^{2}$. Based on cephalometric records congenital missing of one or more teeth was associated with altered craniofacial measurements on a sample of syndrome free Japanese patients as well as in south Indian females ${ }^{3,4}$. Tooth agenesis is frequently a complication of cleft lip cases that is accompanied by alveolar bone deficiency as well ${ }^{5}$. Vitamin D plays a major role in regulation of bone mineralization as it regulates the expression of osteocalcin and osteopontin. Vitamin D receptors (VDR) are expressed by the osteoblasts as their role promotes the effect of vitamin D on bone formation and mineralization ${ }^{6}$. During tooth development the jaw alveolar bone develops around the dental organ from peripheral mesenchymal condensation of the dental follicle cells, that is affected endocrine regulations. the expression of certain cell receptors targeting bone tissue contribute to the alveolar bone development and growth. Such receptors include VDR, for the activated form of vitamin D3, expressed by the differentiated osteoblasts during the initial stages of bone development ${ }^{7}$. RANKL is considered as one of the arms responsible for success and regulation of bone remodeling activity through the enhancement of osteoclast differentiation. Activation of osteoclasts facilitates remodeling through removal of old bone and providing an opportunity for the deposition of new bone. RANKL, as identified as one of the specific markers for bone metabolic activity, is studied in research work combined with histology as well as morphometry investigation to examine bone remodeling features ${ }^{8}$. The present study was intended to investigate the bone quality as well as remodeling potential in alveolar bone sites of congenitally missing teeth compared to other sites of healed extraction.

\section{MATERIALS AND METHODS}

10 core biopsies were collected from the outpatient clinics of the oral and maxillofacial department and from dental implantology department of faculty of dentistry Cairo University. The samples were 5 from healed extraction sites (control) and 5 from sites of congenitally missing teeth (study). They were all from the upper jaw from male subjects with no specification of anterior or posterior teeth.

The collected samples were fixed in $10 \%$ buffered formalin for 48 hours, washed specimens were soaked in $10 \%$ ethylene diamine tetra-acetic acid (EDTA) for 10-14 days for decalcification. Then were dehydrated in ascending grades of alcohol, cleared in xylol then embedded in paraffin. Sections of 4-5 $\mu$ thickness were mounted on regular glass slides. Sections were stained by Hematoxylin and Eosin (H\&E) for routine histological examination following the standard method. Samples were also prepared for quantitative gene expression analysis vitamin $D$ receptors and receptor activator of nuclear factor kappa-B ligand (RANKL) by real time PCR.

\section{Histomorphometry}

Calculations of the total bone area percentage were made on the Hematoxylin and Eosin stained sections,

The data of the area percentage of bone trabeculae was estimated using Leica Quin 500 analyzer computer system, (Leica Microsystems, Swizerland). The image analyzer consisted of a colored video camera, colored monitor, hard disc of IBM personal computer connected to the microscope, and controlled by Leica Qwin 500 software.

Haematoxylin and Eosin stained sections were used to evaluate the total area percentage of bone, after selecting the haematoxylin color of the bone trabeculae with trimming out the areas of bone marrow. The selected color was automatically masked by a blue binary color (fig. 1). The image analyzer is calibrated to convert the measurement units (pixels) produced by the image analyzer program into actual micrometer units. The area percentage was 


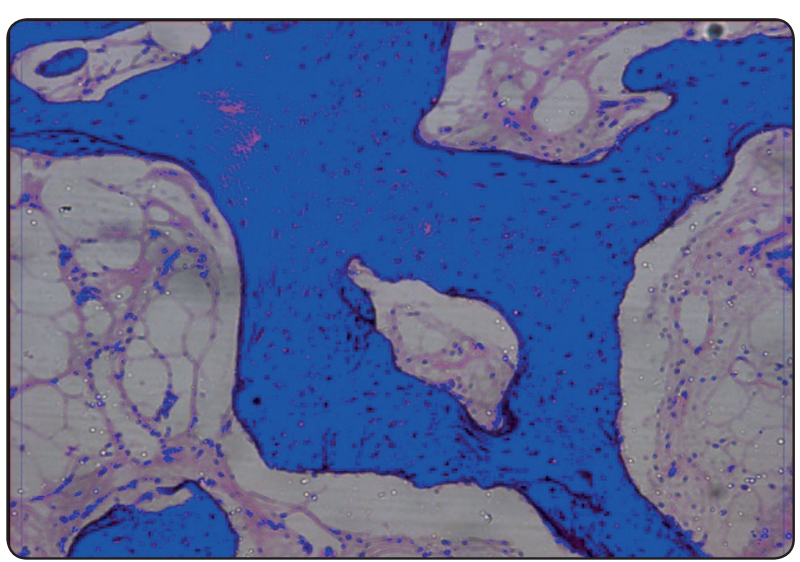

Fig. (1): A photo micrograph showing selection of bone trabeculae masked with the blue binary color for calculation of area percentage (Hematoxylin \& Eosin X200)

estimated in five different fields in each group using magnification (x200). Mean values and standard deviation $(\mathrm{SD})$ were calculated for each of the studied groups.

\section{Real time PCR}

Total RNA was isolated from the tissue paraffin blocks with a total RNA purification kit provided by Jena Bioscience (Munich, Germany) and stored at $-80{ }^{\circ} \mathrm{C}$. RNA was converted into its complementary DNA by cDNA archive kit (Applied Biosystems, Foster City, California, USA). qPCR was performed by using GoTaq PCR master mix (Promega Co., Madison, USA). A protocol that included an initial denaturation step at $95{ }^{\circ} \mathrm{C}$ for 10 minutes, followed by 40 cycles of denaturing at $95{ }^{\circ} \mathrm{C}$ for $15 \mathrm{~s}$, annealing and extension at $60{ }^{\circ} \mathrm{C}$ for 1 minute then $60{ }^{\circ} \mathrm{C}$ for $30 \mathrm{~s}$ was performed on a StepOne Real-Time PCR System (Applied Biosystems, Foster City, California, USA). The following oligonucleotide primers were used: 5'- GATAAATAAGACATGCAATT-3'(sense), 5'GTAGTTTAAAGCATTATCTT-3' (antisense) for RANKL (gene bank accession number AF333234.1), 5'- ACGGGGACTGCCGCATCACC-3'(sense), 5'AGGAGGCCTTGAAGGACAGT-3' (antisense) for Vit D-receptor (gene bank accession number NM_001364085.2), and 5'- GGC GGCACCAC-
CATGTACCCT -3' (sense) and 5'- AGG GGCCGGACTCGTCATACT -3' (antisense) for $\beta$-actin (gene bank accession number NM_001101.3) as an internal control.

\section{Statistical analysis}

Microstat7 for Windows statistical package was used for statistical analysis in this study. Independent student " $t$ " test was used to compare both groups regarding the histomorphometry and the gene expression results. Differences were considered statistically significant at $\mathrm{p} \leq 0.05$.

\section{RESULTS}

\section{Histological results:}

\section{Control group (healed extraction)}

The core biopsies exhibited an intact pattern with interconnecting trabeculae with organized overlapping concentric and interstitial lamellae and well-defined resting lines and reversal lines in between lamellae (fig.2). The bone trabeculae were of varying thicknesses and enclosed variablesized marrow cavities with remaining bone marrow inside. Osteocyte lacunae were distributed evenly between lamellae. (fig.3, A)

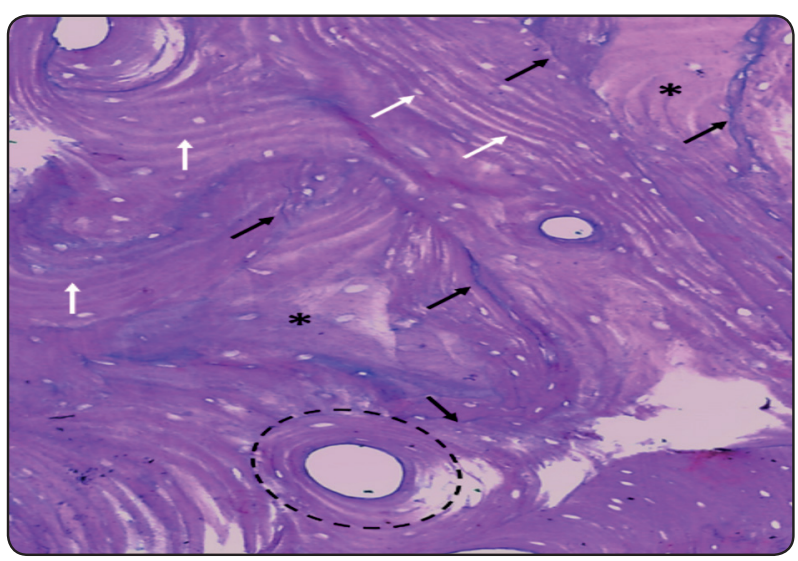

Fig. (2): A photomicrograph of the control group showing; reversal lines (black arrows), resting lines between definite lamellar pattern (white arrows), interstitial lamellae (asterisks) \& concentric lamellae (dashed circle) (Hematoxylin \& Eosin X200) 


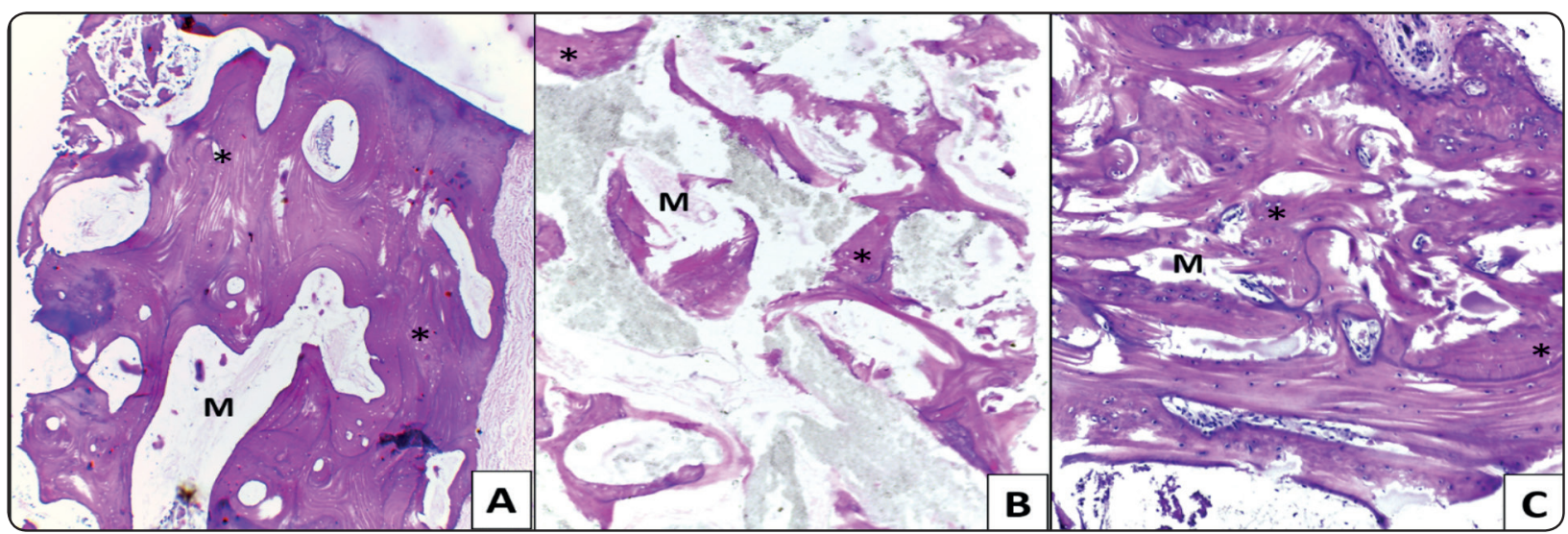

Fig. (3): Photomicrographs showing; A: intact communicating bone trabeculae of the control group (asterisks), B: dispersed widely separated trabeculae in the congenital missing group (asterisks), C: communicating trabeculae with perforated appearance in another specimen of the congenial missing group (asterisks) \& bone marrow (M)appeared in all specimens with variable degrees (Hematoxylin \& Eosin X100)

\section{Study group (congenital missing)}

The biopsies of this group shared a less intact appearance than that detected in control group. Bone varied from being widely separated small sized trabeculae with few connections in between (Fig. 3, B) to another wider communicating pattern. The latter exhibited less solid appearance than the control (fig. 3, C). The common feature between the two patterns is the rarity of incremental resting lines and the indefinite lamellar appearance. Very few



Fig. (4): A photomicrograph of the study group showing; few reversal lines (black arrows), short resting lines between ill-defined lamellae (yellow arrows), (Hematoxylin \& Eosin X200) reversal lines could be seen in the studied specimens (fig.4).

\section{Histomorphometry for total bone area percentage}

Total bone area percentage was calculated for both groups and exhibited elevated values among the healed extraction group with a mean $=43.10$, while the congenitally missing specimens recorded a mean value $=18.52$. the difference between the two groups was statistically significant (P 0.0000). (table, 1 \& fig,5)

TABLE (1): Independent student " $\mathrm{t}$ " test comparing bone area percent in both groups.

\begin{tabular}{|c|c|c|c|c|c|}
\hline \multicolumn{2}{|c|}{$\begin{array}{c}\text { Congenital } \\
\text { missing }\end{array}$} & \multicolumn{2}{|c|}{$\begin{array}{c}\text { Healed } \\
\text { extraction }\end{array}$} & \multirow{2}{*}{ “t” } & \multirow{2}{*}{ Probability } \\
\cline { 1 - 3 } Mean & St Dev & Mean & $\begin{array}{c}\text { St } \\
\text { Dev }\end{array}$ & & \\
\hline 18.52 & 2.12 & 43.10 & 1.91 & 19.277 & $0.0000^{*}$ \\
\hline
\end{tabular}

*= Significant 


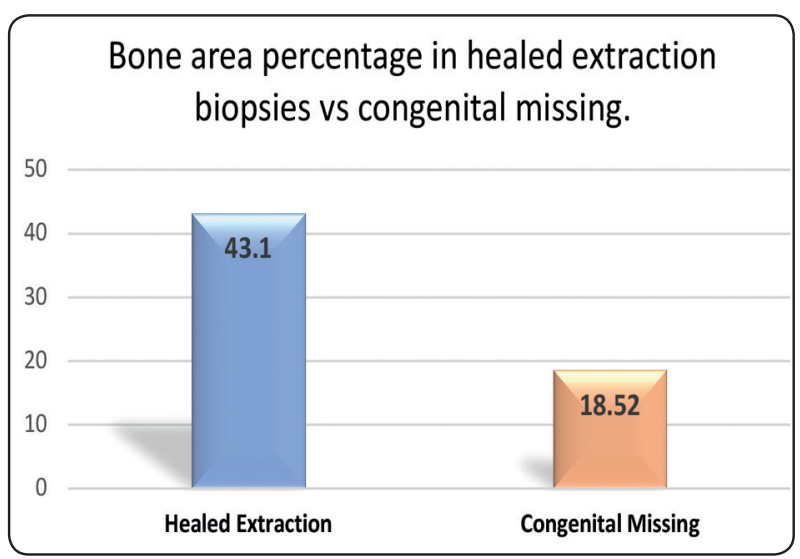

Fig (5): Mean values of Bone area percentage in both groups (healed extraction \& congenital missing).

\section{Gene expression results}

Both Vitamin "D" receptors and RANKL recorded higher mean values in healed extraction group (means $=1.50 \& 1.12$ for VDR \& RANKL respectively) than in congenitally missing group (means $=0.62 \& 0.58$ for VDR \& RANKL respectively) and the difference was statistically significant $(\mathrm{P}=0.0000)$. (table 2 \& fig. 6$)$

TABLE (2): Independent student " $t$ " test comparing gene expression values in both groups

\begin{tabular}{|l|c|c|c|c|c|c|}
\hline & \multicolumn{2}{|c|}{$\begin{array}{c}\text { Healed } \\
\text { Extraction }\end{array}$} & \multicolumn{2}{|c|}{$\begin{array}{c}\text { Congenitally } \\
\text { Missing }\end{array}$} & \multirow{2}{*}{ "t” } & \multirow{2}{*}{ Probability } \\
\cline { 2 - 5 } & Mean & $\begin{array}{c}\text { St } \\
\text { Dev }\end{array}$ & Mean & St Dev & & \\
\hline $\begin{array}{l}\text { Vitamin D } \\
\text { Receptors }\end{array}$ & 1.50 & 0.34 & 0.62 & 0.12 & 6.979 & $0.0000^{*}$ \\
\hline RANKL & 1.12 & 0.16 & 0.58 & 0.13 & 7.626 & $0.0000^{*}$ \\
\hline
\end{tabular}

*= Significant



Fig (6): Mean values of vitamin "D" receptors and RANKL in both groups.

\section{DISCUSSION}

The present research was a preliminary investigation on the bone morphology and physiologic in congenital tooth missing sites. A hint that may be helpful in the prediction of future implant success or failure in such area and to open a channel for more investigation in this field. The study samples were core biopsied collected from male patients during the drilling for implant fixation in the maxilla. The present results revealed different histological features in the group of congenital missing in relation to healed extraction group. Less intact small bone trabeculae with few ill-defined incremental lines were exhibited in the congenital missing group in relation to the interconnecting larger bone trabeculae with multiple well-defined resting lines in control. The general view of bone histology denoted a decreased activity that was further confirmed by lower bone area percentage in the congenital missing group. Furthermore, gene expression was performed for vitamin D receptors VDR and for receptor activator of NFxB ligand (RANKL) for being two genes involved in bone formation and remodeling, respectively.

In previous literature studies on the dental follicle suggested its role in alveolar bone development. Dental follicle cells are essential elements for 
the development of periodontal tissues including periodontal ligament, cementum and alveolar bone. Follicle cells are involved tooth eruption, root and alveolar bone morphogenesis as they eventually differentiate into osteoblasts cementoblasts and fibroblasts. ${ }^{9}$

Runex 2 gene is expressed by the dental follicle which directly affects bone formation by stimulating the differentiation of osteoblasts which normally express RANKL and other regulatory genes ${ }^{10}$. The differentiated osteoblasts from the dental follicle cells express RANKL and OPG which act together as regulatory factors for osteoclast differentiation ${ }^{11}$. Ripamonti added that during tooth development, cementum matrix produces morphogenetic signals capable of inducing bone formation $^{12}$. The dental follicle existence was proved to be crucial for development of the periodontium and specifically the epithelial cells of Hertwig as they were found to participate in periodontal development and regeneration ${ }^{13}$.

Uribe, et $\mathrm{al}^{14}$ discovered that the dental follicle was involved in the bone formation process during eruption when compared gene expression of osteocalcin, Runex-2 and alkaline phosphatase in case of impaction or normal eruption. However, they found no significant difference in remodeling genes like OPG, and RANKL $\mathrm{n}$ their studied groups which may not coincide with the present findings regarding a suggested role of the follicle in remodeling. Meanwhile, it helps to figure the relation between the presence of the dental follicle and bone development in the area of interest.

Tudpor et al ${ }^{15}$ concluded that bone remodeling activity is maintained by upregulation of RANKL and down regulation of OPG under the influence of thrombin/receptor system in mice. A conclusion that stresses on the importance of RANKL as a gene controlling bone remodeling. That explains the rare resting lines detected in the studied samples of congenitally missing core biopsies.
Moreover, Uribe et al ${ }^{16}$ studied RANKL expression in extracted human dental follicle cells (HDFCs) which was more expressed in the coronal part of the follicle than in the apical part using quantitative real time PCR. They concluded that its expression between individuals may change according to clinical variation in tooth eruption. Hence, it can be assumed that clinical variation of tooth existence or absence may also affect the gene expression and vice versa.

RANKL is considered as one of the key genes responsible for bone remodeling, together with OPG, that recorded a significantly increased expression with active orthodontic movement in experimental procedure ${ }^{17}$. That confirms the relation between osteoclastogenesis and bone remodeling. The present results recorded lower values of RANKL in congenital missing when compared to healed extraction which suggests a better bone activity among the healed extraction group that can be attributed to lack of gene expression by the absent dental follicle cells.

The current results revealed decreased bone area in the congenitally missing group with reduced RANKL levels in the same group. Moreover, Canullo et al ${ }^{8}$ tried to find a correlation between histomorphometric findings and gene expression values in bone metabolism although they detected the expression of proteins including RANKL, OPG, RANK. They couldn't correlate with histomorphometry results in their study.

Although the expression of RANKL was linked to osteopenia in lactating mice by Macari, et al ${ }^{18}$ it was found that the increased expression of RANKL RANK \& OPG resulted in increased bone remodeling and enhanced orthodontic tooth movement. In addition, Li et al ${ }^{19}$ proved that the injection of RANKL in mice facilitated tooth movement through induction of osteoclast differentiation and bone resorption with subsequent stimulation of new bone formation which explains the effect of the gene on bone remodeling and formation. PU and HUA also 
reported that upregulation of RANKL proved better remodeling activity that facilitated orthodontic tooth movement in a mouse model ${ }^{20}$. This adds to the validity of the gene investigation in the current research.

Vitamin D is known to regulate Calcium absorption and bone mineralization and it was reported to be involved in different bone metabolic activities ${ }^{21}$. Regulatory enzymes for vitamin D action on bone are expressed by different bone cells like osteoblasts. Among these enzymes is vitamin D receptors VDR thus the level of expression of such enzymes can be linked to bone activity either negatively or positively ${ }^{22}$. That can explain the morphometric and the gene expression results of the herein study when the congenital missing group exhibited lower values for VDR with recorded lower bone area percentages as well as lower RANKL expression. This can corelate and suggest a negative effect of the absent dental follicle on alveolar bone development in congenital tooth missing locations studied in the herein research.

Osteoblasts differentiation from bone marrow stem cells in vitro was believed to be stimulated by the local treatment with parathormone \& vitamin D receptor ${ }^{23}$. Back to the present findings the decrease in vitamin $\mathrm{D}$ receptor can explain that the reduced bone area percentage among the congenital tooth missing group may be due to decreased osteoblastic differentiation with consequent defective bone formation. Moreover, the decreased differentiation of osteoblasts will result in decreased expression of RANKL, produced originally by osteoblasts, in the same study group.

Alvim-Pereira et $\mathrm{al}^{24}$ failed to find any association between failure of osseointegration around implants and the genotypic variation of VDR gene which didn't agree with the present findings. In 2019 , Pereira et $\mathrm{al}^{25}$ suggested a possible role of allele $\mathrm{G}$ of rs 3782905 of VDR in the recessive model may in dental implant loss in patients who lost two or more dental implants. The authors recommended further replication of their study to confirm their findings. This, to some extent, can be useful to apply the current findings of VDR values regarding the expectations of implant survival for the studied samples' sites. On the other hand, it is important to determine which allele of VDR that may obtain such relation with alveolar bone activity in the current study as the gene exhibits a polymorphic nature that makes different forms produce different effects bone tissue. Ratheesh etal failed to find any association between TaqI allels of VDR and severe chronic periodontitis, with massive alveolar bone loss, in a study made in an Ethnic Tamilian population.

Chen et $\mathbf{a l}^{26}$ analyzed bone remodeling around the mandibular molar primordia of mice by finite element methods. Their results supported Blechschmidt's hypothesis that the bone in general is created under the influence of shear forces. This can be reliable to confirm the findings of the herein research counting on the presence of a tooth structure to create such forces to induce bone formation around. The presence of a tooth with actual eruption movement, either intra-boney or extra-bony, creates a series of compressions and tensions that trigger bone changes. What happens if this tooth is missing? The intimate surrounding alveolar bone will lack these inducing forces although the rest of the jawbone is developing normally. The real problem is related to that narrow part of alveolar bone involved with the periodontium to be of the missing tooth. Congenital tooth absence will consequently suppress these forces which creates an area of defective activity.

In conclusion, the results suggested a difference in bone morphological and physiological features in alveolar bone areas of congenital tooth absence when compared to areas of healed extraction sites. The present study may not have involved all research points or markers that can be helpful in better understanding of the difference in bone activity in areas of congenital tooth absence compared to normally erupted teeth. Few points were covered, for being a pilot attempt, in order to release some highlights for further and more detailed investigation. 


\section{REFERENCES}

1. Kokich V, Kinzer G. Managing congenitally missing lateral incisors. Part I: Canine substitution. J Esthet Restor Dent. 2005;17(1):5-10. http://onlinelibrary.wiley.com/ doi/10.1111/j.1708-8240.2005.tb00076.x/abstract.

2. Rakhshan V. Congenitally missing teeth (hypodontia): A review of the literature concerning the etiology, prevalence, risk factors, patterns and treatment. Dent Res J (Isfahan). 2015;12(1):1-13. doi:10.4103/1735-3327.150286

3. Takahashi Y, Higashihori N, Yasuda Y, Takada J ichi, Moriyama K. Examination of craniofacial morphology in Japanese patients with congenitally missing teeth: a crosssectional study. Prog Orthod. 2018;19(1). doi:10.1186/ s40510-018-0238-9

4. Kishore Kumar S, Vidhya Lakshmi A V., Namita S, Elumalai M. Craniofacial morphologic variations and its association with hypodontia pattern (Anterior) in South Indian female population. Biosci Biotechnol Res Asia. 2013;10(1):325-328. doi:10.13005/bbra/1129

5. Vuletić M, Knežević P, Jokić D, Rebić J, Žabarović D, Macan D. Alveolar Bone Grafting in Cleft Patients: from Bone Defect to Dental Implants. Acta Stomatol Croat. 2014;48(4):250-257. doi:10.15644/asc48/4/2

6. Kraichely DM, MacDonald PN. Transcriptional activation through the vitamin D receptor in osteoblasts. Front Biosci. 1998;3. doi:10.2741/a325

7. Bobek J, Oralova V, Lesot H, Kratochvilova A, Doubek J, Matalova E. Onset of calciotropic receptors during the initiation of mandibular/alveolar bone formation. Ann Anat. 2020;227:151427. doi:10.1016/j.aanat.2019.151427

8. Canullo L, Pellegrini G, Canciani E, Heinemann F, Galliera E, Dellavia C. Alveolar socket preservation technique: Effect of biomaterial on bone regenerative pattern. Ann Anat. 2016;206:73-79. doi:10.1016/j.aanat.2015.05.007

9. Zhou T, Pan J, Wu P, et al. Dental Follicle Cells: Roles in Development and beyond. Stem Cells Int. 2019;2019. doi:10.1155/2019/9159605

10. Pan K, Sun Q, Zhang J, et al. Multilineage differentiation of dental follicle cells and the roles of Runx 2 over-expression in enhancing osteoblast/cementoblast-related gene expression in dental follicle cells. Cell Prolif. 2010;43(3):219228. doi:10.1111/j.1365-2184.2010.00670.x

11. Sun H, Li Q, Zhang Y, et al. Regulation of OPG and RANKL expressed by human dental follicle cells in os- teoclastogenesis. Cell Tissue Res. 2015;362(2):399-405. doi:10.1007/s00441-015-2214-8

12. Ripamonti U. Developmental pathways of periodontal tissue regeneration: Developmental diversities of tooth morphogenesis do also map capacity of periodontal tissue regeneration? J Periodontal Res. 2019;54(1):10-26. doi:10.1111/jre.12596

13. Guo Y, Guo W, Chen J, Chen G, Tian W, Bai D. Are Hertwig's epithelial root sheath cells necessary for periodontal formation by dental follicle cells? Arch Oral Biol. 2018;94(March):1-9. doi:10.1016/j.archoralbio.2018.06.014

14. Uribe P, Larsson L, Westerlund A, Ransjö M. Gene expression profiles in dental follicles from patients with impacted canines. Odontology. 2018;106(4):351-359. doi:10.1007/ s10266-018-0342-9

15. Tudpor K, van der Eerden BCJ, Jongwattanapisan P, et al. Thrombin receptor deficiency leads to a high bone mass phenotype by decreasing the RANKL/OPG ratio. Bone. 2015;72:14-22. doi:10.1016/j.bone.2014.11.004

16. Uribe P, Plakwicz P, Larsson L, Czochrowska E, Westerlund A, Ransjö M. Study on site-specific expression of bone formation and resorption factors in human dental follicles. Eur J Oral Sci. 2018;126(6):439-448. doi:10.1111/ eos. 12568

17. Baloul SS, Gerstenfeld LC, Morgan EF, Carvalho RS, Van Dyke TE, Kantarci A. Mechanism of action and morphologic changes in the alveolar bone in response to selective alveolar decortication-facilitated tooth movement. Am J Orthod Dentofac Orthop. 2011;139(4 SUPPL.):S83-S101. doi:10.1016/j.ajodo.2010.09.026

18. Macari S, Sharma LA, Wyatt A, et al. Lactation induces increases in the RANK/RANKL/OPG system in maxillary bone. Bone. 2018;110(2017):160-169. doi:10.1016/j. bone.2018.01.032

19. Li C, Chung CJ, Hwang CJ, Lee KJ. Local Injection of RANKL Facilitates Tooth Movement and Alveolar Bone Remodelling. Vol 25.; 2019. doi:10.1111/odi.13013

20. $\mathrm{Pu} \mathrm{H}$, Hua Y. Hydrogen sulfide regulates bone remodeling and promotes orthodontic tooth movement. Mol Med Rep. 2017;16(6):9415-9422. doi:10.3892/mmr.2017.7813

21. Sharma DK, Sawyer RK, Robertson TS, et al. Elevated Serum 25-Hydroxyvitamin D Levels Are Associated with Improved Bone Formation and Micro-Structural Measures in Elderly Hip Fracture Patients. 25:1-10. doi:10.3390/ jem8111988 
22. Anderson PH. Vitamin D Activity and Metabolism in Bone. Curr Osteoporos Rep. 2017;15(5):443-449. doi:10.1007/ s11914-017-0394-8

23. S Genga, S Zhoub, Z Bia, and J Glowackib. Vitamin D Metabolism in Human Bone Marrow Stromal (Mesenchymal Stem) Cells. Metabolism. 62(6):768-777. doi:10.1016/j. metabol.2013.01.003.

24. Alvim-Pereira F, Montes CC, Thomé G, Olandoski M, Trevilatto PC. Analysis of association of clinical aspects and vitamin $\mathrm{D}$ receptor gene polymorphism with dental implant loss. Clin Oral Implants Res. 2008;19(8):786-795. doi:10.1111/j.1600-0501.2008.01532.x

25. Munhoz Pereira T, Alvim-Pereira F, Kaiser Alvim-Pereira CC, Ignácio SA, Machado de Souza C, Trevilatto PC. A complete physical mapping of the vitamin $\mathrm{D}$ receptor gene for dental implant loss: A pilot study. Clin Oral Implants Res. 2019;(July):1-14. doi:10.1111/clr.13529

26. Chen J, He Y, Keilig L, et al. Numerical investigations of bone remodelling around the mouse mandibular molar primordia. Ann Anat. 2019;222:146-152. doi:10.1016/j. aanat.2018.12.009 